\title{
AS RELAÇÕES ENTRE A FORMAÇÃo DO PNAIC E AS PRÁTICAS DE ALFABETIZAÇÃO
}

\author{
Andreia Martinazzo Braga (PPGEd/UNOESC)* \\ https://orcid.org/0000-0003-4130-3887 \\ Nadiane Feldkercher (PPGEd/UNOESC)** \\ http://orcid.org/0000-0002-8208-3369
}

\section{RESUMO}

Alfabetizar envolve a apropriação das práticas de leitura e de escrita pelos aprendizes, o que determina tanto a formação quanto as práticas pedagógicas dos professores alfabetizadores. Neste trabalho objetivamos identificar e analisar quais aspectos da formação do Pacto Nacional Pela Alfabetização na Idade Certa (PNAIC) fazem parte das práticas alfabetizadoras das professoras após as etapas desta formação. A investigação teve uma abordagem qualitativa, com procedimentos de coleta de dados por meio de entrevistas com seis professoras alfabetizadoras. Os dados coletados foram trabalhados a partir da análise de conteúdo. Os resultados apontam que a formação do PNAIC trouxe contribuições para as práticas, incluindo o aprofundamento de teorias, a melhor compreensão da avaliação dos níveis de escrita dos alunos, a ampliação do uso da ludicidade, a importância do planejamento e o melhor entendimento da função social da leitura e da escrita. Evidenciamos que o PNAIC foi relevante para as professoras alfabetizadoras, sendo significativo para seus processos de formação docente e para a ressignificação de suas práticas.

Palavras-chave: Professoras alfabetizadoras. Práticas de alfabetização. PNAIC.

\section{ABSTRACT}

\section{RELATIONS BETWEEN PNAIC TRAINING AND LITERACY PRACTICES}

Literacy involves the appropriation of reading and writing practices by learners, which determines both the training and pedagogical practices of literacy teachers. In this paper, we aim to identify and analyze which aspects of the formation of the National Pact for Literacy at the Right Age (PNAIC) are part of the teachers' literacy practices after the stages of this formation. The research

\footnotetext{
* Mestre em Educação pela Universidade do Oeste de Santa Catarina (UNOESC). Professora alfabetizadora da Rede Municipal de Piratuba, SC. Pesquisadora integrante do Grupo de Pesquisa Formação Docente e Práticas de Ensino do Programa de PósGraduação em Educação da Universidade do Oeste de Santa Catarina (PPGEd/UNOESC). E-mail: andreiamartinazzobraga@ gmail.com

** Doutora em Educação pela Universidade Federal de Pelotas (UFPel). Docente do Programa de Pós-Graduação em Educação da Universidade do Oeste de Santa Catarina (PPGEd/UNOESC). Líder do Grupo de Pesquisa Formação Docente e Práticas de Ensino do Programa de Pós-Graduação em Educação da Universidade do Oeste de Santa Catarina (PPGEd/UNOESC). E-mail: nadiane.feldkercher@unoesc.edu.br
} 
had a qualitative approach with data collection procedures through interviews with six literacy teachers. The collected data were worked from the content analysis. The results show that the formation of the PNAIC brought contributions to the practices, including the deepening of theories, a better understanding of the assessment of students' writing levels, the broader use of playfulness, the importance of planning and a better understanding of social function of reading and writing. We evidenced that the PNAIC was relevant for the literacy teachers, being significant for their processes of teacher formation and for the resignification of their practices.

Keywords: Literacy teachers. Literacy practices. PNAIC.

\section{RESUMEN}

\section{LAS RELACIONES ENTRE LA FORMACIÓN DE PNAIC Y LAS PRÁCTICAS DE ALFABETIZACIÓN}

La alfabetización implica la apropiación de las prácticas de lectura y escritura por parte de los alumnos, lo que determina tanto la educación como las prácticas pedagógicas de los maestros de alfabetización. En este artículo pretendemos identificar y analizar qué aspectos de la formación del Pacto Nacional para la Alfabetización en la Edad Adecuada (PNAIC) son parte de las prácticas de alfabetización de los docentes después de las etapas de esta formación. La investigación tuvo un enfoque cualitativo con procedimientos de recolección de datos a través de entrevistas con seis maestros de alfabetización. Los datos recopilados se trabajaron a partir del análisis de contenido. Los resultados muestran que la formación del PNAIC aportó contribuciones a las prácticas, incluida la profundización de las teorías, una mejor comprensión de la evaluación de los niveles de escritura de los estudiantes, el uso más amplio del juego, la importancia de la planificación y una mejor comprensión de la función social de la lectura y de la escritura Evidenciamos que el PNAIC fue relevante para los maestros de alfabetización, siendo significativo para sus procesos de formación docente y para la resignificación de sus prácticas.

Palabras clave: Alfabetización docente. Prácticas de alfabetización. PNAIC.

\section{Introdução $0^{1}$}

No decorrer do ciclo de alfabetização, diversas práticas educativas são desenvolvidas pelos professores. Tais ações incluem tanto decisões dentro da sala de aula como decisões que a transcendem. Para Franco (2012), a prática pedagógica de alfabetização convive com decisões que antecedem a prática de sala

1 Essa pesquisa foi desenvolvida conforme Resolução CNS no 466/12 e aprovada pelo Comitê de Ética em Pesquisa da Universidade do Oeste de Santa Catarina (UNOESC), sob CAAE número 07389118.4.0000.5367 e parecer número 3.174.249, em 27 de fevereiro de 2019 . de aula. Essas decisões apresentam aspectos relacionados com os enfoques epistemológicos a serem utilizados, os materiais didáticos de suporte e os métodos que devem ser priorizados. Essa autora cita haver decisões que extrapolam a sala de aula e que a prática de letramento supõe esforço familiar e social para vivência de práticas de leitura de mundo. Neste sentido as práticas alfabetizadoras tendem a se adequar com a realidade do contexto social apresentado. 
Segundo Ferreiro e Teberosky (1979, p. 8)

[...] a mão que escreve e o olho que lê estão sob um comando de um cérebro que pensa sobre a escrita que existe em seu meio social e com a qual toma contato através da sua própria participação em atos que envolvem o ler ou o escrever, em práticas sociais mediadas pela escrita.

Esses apontamentos das autoras ajudam a perceber que a criança ao chegar na escola traz consigo vivências sociais relacionadas aos conhecimentos referentes à sua cultura letrada e isso a ajudará na construção de seu próprio conhecimento da linguagem escrita. Dessa maneira, compreendemos que as práticas educativas se encontram vinculadas à questão social.

Ferreiro (1988) destaca que durante o processo de alfabetização devem ser sistematicamente consideradas as influências e modelos sociais, os quais exercem diversas funções a depender do momento de desenvolvimento, visto que não são recebidos passivamente pelas crianças, sendo necessário, portanto, compreender os mecanismos precisos de interação com a realidade social. Isto é, os princípios organizadores do desenvolvimento da leitura e da escrita não podem ser derivados somente da experiência externa ou interna, mas dependem de todas as experiências do aprendiz.

Dentro dessa mesma perspectiva, Soares (2008) argumenta que a importância da alfabetização depende da função que lhe é atribuída no contexto social. Isto ao considerar que dentro da ideologia hegemônica das culturas grafocêntricas não há possibilidade de participação econômica, política, social e cultural plena sem o domínio da língua escrita. Também não há possibilidade de participação nos bens simbólicos sem o acesso à leitura como bem cultural.

Compreendemos que a "alfabetização é um elemento importante, pois saber ler e escrever é condição necessária à participação na sociedade letrada em que vivemos" (CAGLIARI, 1993, p. 10). A partir dessa concepção de alfabetização, compreende-se o papel fundamental do professor alfabetizador, que contribui para com o processo de humanização de cada um de seus alunos.

A partir da teoria da Psicogênese da Língua Escrita, Ferreiro e Teberosky (1979) expressam a ideia de que a aprendizagem da leitura e da escrita não se dá espontaneamente. Ao contrário, exige uma ação deliberada do professor e, portanto, uma qualificação profissional. Também exige planejamento e decisões a respeito do tipo, frequência, diversidade e sequência das atividades relacionadas ao ato de aprender a leitura e a escrita.

De tal modo, a dimensão da prática docente do professor alfabetizador relaciona-se aos diversos elementos que impulsionam e orientam o processo de ensinar a ler e a escrever com compreensão, bem como desenvolver capacidades para identificar e utilizar códigos e regras. Para que o ensino ocorra, o alfabetizador precisa estar qualificado nos domínios dos conceitos das teorias da aprendizagem, no processo de construção da escrita, nas estratégias de leitura e em demais conhecimentos necessários ao processo. Todos esses conhecimentos necessários às práticas alfabetizadoras trazem constantemente necessidades de formação específica para alfabetizar. Mas como suprir tais demandas?

Com a intenção de promover mudanças em relação ao nível de desempenho nos processos de alfabetização e buscando qualificar os profissionais da Educação Básica envolvidos, o Governo Federal, por meio do Ministério de Educação (MEC), ofereceu programas específicos de estudo, reflexão e implementação de práticas para professores alfabetizadores, na tentativa de alfabetizar os estudantes brasileiros nos primeiros anos do ensino fundamental. Um desses programas de formação continuada foi o Pacto Nacional pela Alfabetização na Idade Certa (PNAIC), instituído em 2012, implantado em 2013 e finalizado em 2018. 0 PNAIC teve como principal objetivo garantir que todas as crianças brasileiras, até oito anos de idade, fossem plenamente alfabetizadas e contou com a participação da União, estados, 
municípios e instituições de todo o país, envolvendo um número expressivo de professores alfabetizadores.

Com fins de explorar os estudos já realizados sobre a temática, realizamos, em meados de 2018, um levantamento dos trabalhos disponibilizados no Catálogo de Teses e Dissertações da Coordenação de Aperfeiçoamento de Pessoal de Nível Superior (CAPES). Mediante a utilização combinada dos descritores "Professoras alfabetizadoras" e "PNAIC", encontramos trabalhos de abrangência nacional, produzidos entre 2013 e 2018. Estas pesquisas contaram, em sua grande maioria, com a participação de professoras alfabetizadoras que realizaram a formação continuada do PNAIC. Ainda, encontramos trabalhos que tiveram como participantes coordenadores locais, orientadores de estudos do PNAIC e, em alguns trabalhos, coordenadoras pedagógicas das secretarias municipais de educação dos municípios onde as pesquisas foram realizadas. Em totalidade esses estudos envolveram contextos escolares. Pelos diferentes contextos estudados - escolas localizadas na zona urbana, rural, em periferias e em comunidades indígenas -, percebe-se a diversidade cultural tanto nos contextos de formação quanto na atuação das professoras alfabetizadoras.

A partir das análises dos estudos foi possível identificar algumas demandas não exploradas, tais como: as práticas alfabetizadoras interdisciplinares no ciclo de alfabetização com o viés proposto pela formação do PNAIC e as práticas pedagógicas propostas pelo PNAIC presentes nos fazeres diários das professoras alfabetizadoras após esse período de formação continuada. Assim, a realização desta pesquisa justifica-se pela importância da atuação das professoras alfabetizadoras no meio educativo, bem como pela necessidade de um estudo sobre as percepções do processo formativo e das repercussões nas práticas pedagógicas, a partir do ponto de vista das professoras alfabetizadoras que participaram do PNAIC.
Levando em consideração as preocupações referentes à alfabetização e os programas federais de formação continuada para alfabetizadores, desenvolvemos uma investigação maior que objetivou investigar, segundo as percepções das professoras alfabetizadoras de um município do Oeste do Estado de Santa Catarina, as decorrências do PNAIC em suas formações continuadas e em suas práticas alfabetizadoras (BRAGA, 2019). Neste trabalho apresentamos parte dessa investigação, objetivando identificar e analisar quais aspectos da formação do Pacto Nacional Pela Alfabetização na Idade Certa (PNAIC) fazem parte das práticas alfabetizadoras das professoras após as etapas desta formação.

O contexto da pesquisa empírica abrangeu professoras das escolas da rede pública municipal de uma cidade localizada no Oeste do estado brasileiro de Santa Catarina. A amostra foi constituída por seis professoras alfabetizadoras que participaram das etapas da formação do PNAIC entre os anos de 2013 e 2018, no município pesquisado. Os critérios de inclusão das participantes da pesquisa foram: 1) ser professora alfabetizadora na rede municipal de ensino do município pesquisado; 2) atuar no ciclo de alfabetização, correspondente ao primeiro, segundo e terceiro ano do ensino fundamental dos anos iniciais; 3) ter participado de alguma das etapas da formação continuada do Pacto Nacional Pela Alfabetização na Idade Certa (PNAIC); e 4) assinar o Termo de Consentimento Livre e Esclarecido (TCLE). A fim de preservar a identidade de cada uma das professoras alfabetizadoras, são identificadas no texto por meio de nomes fictícios por elas sugeridos.

O procedimento de coleta de dados ocorreu por meio de entrevista individual, com roteiro semiestruturado. Os dados foram trabalhados a partir da análise de conteúdo e evidenciaram três categorias analíticas: as práticas alfabetizadoras anteriores ao PNAIC, as práticas alfabetizadoras posteriores ao PNAIC e os impactos do PNAIC para a aprendizagem dos alunos. 
Na sequência do texto apresentamos as bases teóricas que sustentaram essa pesquisa, os dados coletados e analisados e, por fim, algumas sínteses do nosso estudo sobre a formação e as práticas de professoras alfabetizadoras

\section{Formação e práticas de professoras alfabetizadoras}

0 ensino da alfabetização é um processo complexo que requer uma boa formação teórica para o professor, que o capacite para a compreensão de como se dá a construção do conhecimento pela criança e, também, o auxilie na aquisição e no desenvolvimento de habilidades que facilitem o sucesso no processo de alfabetizar.

De acordo com Ferreiro (1999, p. 47), a "alfabetização não é um estado ao qual se chega, mas um processo cujo início é na maioria dos casos anterior a escola e que não termina ao finalizar a escola primária". Além de considerar a alfabetização como algo processual e inconcluso, essa autora enfatiza que o processo de alfabetização - enquanto conceito - também muda de acordo com as épocas, as culturas e a chegada das tecnologias.

Já para Soares (2003, p. 12), a alfabetização, na concepção atual, "desenvolve-se no contexto de uma vivência intensa e diversificada pela criança dos usos e práticas sociais da língua escrita". Para essa autora, a sala de aula de alfabetização tem um duplo objetivo. O primeiro volta-se em ajudar as crianças por meio da reflexão sobre as características dos diferentes textos que circulam ao seu redor, sobre seus estilos, usos e finalidades. Segundo, a sala de aula da alfabetização constitui-se na ajuda às crianças se apropriarem do sistema de escrita, para que tenham autonomia para interagir por meio da escrita. Assim, entendemos que a formação do professor alfabetizador deve voltar-se, principalmente, ao desenvolvimento da capacidade de ensinar os alunos a aprenderem.
Na percepção de Vieira (2015) ser alfabetizador comporta, antes de tudo, ter clareza de sua prática. Para a autora essa compreensão leva o professor a incentivar a criança a conhecer o mundo, a se comunicar e se expressar, o que colabora com seu processo de alfabetizar-se. A criança só começa a ler quando descobre que o mundo é feito de coisas concretas que podem ser vistas, tocadas, dramatizadas, imitadas, desenhadas, cantadas, fotografadas, descobertas. Isso fortalece a alfabetização das crianças. É preciso, então, que o professor entenda que a criança necessita fazer essa descoberta para ser alfabetizada, para vivenciar a prática social da leitura e da escrita (VIEIRA, 2015).

Ainda, segundo Bolzan e Millani (2013), pensar sobre a docência alfabetizadora implica compreender como se desenvolve essa atividade docente, uma vez que se entende que a construção da identidade profissional está intrinsecamente relacionada às vivências dos professores em seu espaço de atuação, ou seja, na escola. Essas autoras argumentam que a alfabetização é uma função historicamente reconhecida como desafiadora, pois envolve uma atividade pedagógica com múltiplos resultados ao final de um ciclo. Alfabetizar envolve um trabalho de apropriação das práticas de leitura e de escrita pelos aprendizes, o que determina a competência do professor para tal função. Para Bolzan e Millani (2013), por ser desafiadora, a alfabetização nem sempre é assumida voluntariamente pelos professores. Muitas vezes os docentes alfabetizadores não se veem preparados para tal atividade, e no próprio exercício profissional é que constroem estratégias para atender às exigências dessa prática educativa.

Conforme encontramos registrado no Caderno de Apresentação do PNAIC (BRASIL, 2012a), no mínimo, o alfabetizador precisa atender aos seguintes critérios para atuar nos anos iniciais do Ensino Fundamental: 1) ter domínio dos conhecimentos necessários ao desenvolvimento do ensino da leitura e da escrita na perspectiva do letramento; 2) ter habilidades 
para interagir com as crianças, dinamizando o processo pedagógico e promovendo situações lúdicas de aprendizagem; 3) ser assíduo e pontual, evidenciando compromisso com os processos pedagógicos; e 4) ter sensibilidade para lidar com a diversidade social, cultural, de gênero e etnia. Nestes requisitos verificamos a necessidade do professor de compreender a alfabetização enquanto um processo que deve integrar a aprendizagem do Sistema de Escrita Alfabética (SEA) aos conhecimentos e habilidades que venham a favorecer a conexão das crianças com os textos orais e escritos que circulam no meio social. Neste sentido, a escola precisa dispor de variados recursos didáticos pedagógicos que, ao mesmo tempo, venham a favorecer a reflexão sobre a língua e também possibilitar a realização de atividades de produção e compreensão destes textos orais e escritos. A atuação do professor alfabetizador exige domínio de conteúdo, habilidades didáticas-pedagógicas para aproximar-se de seus alunos e sensibilidade para perceber as reais necessidades que o meio educativo apresenta.

Diante dessas demandas de ensino, os professores necessitam atualizar-se continuamente, para estarem preparados para enfrentar esses desafios. Soares (2008) enfatiza que a formação do alfabetizador tem uma grande especificidade, exige uma preparação do professor que o leve a compreender todas as facetas (psicológica, psicolinguística e linguística) e todos os condicionantes (sociais, culturais, políticos) do processo de alfabetização. Essa autora argumenta que esse profissional necessita, a partir dessas facetas e condicionantes, operacionalizar os métodos e procedimentos para promover a alfabetização, o que envolve elaboração e uso adequados de materiais didáticos. Destaca ainda que o papel do alfabetizador exige uma postura política diante das implicações ideológicas do significado atribuído à alfabetização.

Certamente o trabalho do professor alfabetizador é importante e significativo. Devido à importância da alfabetização para o câmbio social, vemos o surgimento de algumas políticas públicas educacionais que reconhecem a alfabetização como uma prioridade para o país. Ainda que com essa importância e reconhecimento, o trabalho de alfabetizar não é uma tarefa fácil. A partir de nossa experiência como professoras alfabetizadoras, identificamos alguns desafios dessa tarefa, a saber: 1) o diagnóstico e a caracterização do nível de escrita da criança; 2) a adequação do planejamento para trabalhar com a diversidade de uma sala de aula de alfabetização; 3) a alfabetização na perspectiva do letramento; e 4) a avaliação do processo de ensino e aprendizagem no ciclo de alfabetização - os quais exploramos na sequência.

O diagnóstico e a caracterização do nível de escrita no qual a criança se encontra auxilia o professor na organização das prioridades pedagógicas a serem desenvolvidas no decorrer do processo de alfabetização. Portanto, cabe ao professor identificá-lo. Segundo os estudos da psicogênese da língua escrita de Ferreiro e Teberosky (1979), os aprendizes passam por quatro períodos nos quais têm diferentes hipóteses de como a escrita alfabética funciona, a saber: $1^{\circ}$ período: nível pré-silábico; $2^{\mathrm{o}}$ período: nível silábico; $3^{\circ}$ período: nível silábico alfabético; e 4oㅡónodo: nível alfabético. Conforme essas autoras, para se alfabetizar, a criança precisa perceber que o que a escrita alfabética registra no papel são os sons das partes orais das palavras e que o faz considerando segmentos sonoros menores que a sílaba. Compreender com propriedade todo esse processo de construção da aprendizagem do sistema de escrita alfabética tende a auxiliar o professor alfabetizador a ter maior clareza de quais metodologias são necessárias para auxiliar as crianças a avançar de um nível de escrita para o outro e consolidar o processo de alfabetização.

Para Soares (2003), o professor deverá organizar o processo de construção da leitura e da escrita de forma sistemática e metodológica. É importante que as atividades planejadas para 
serem desenvolvidas com os alunos das turmas de alfabetização possam facilitar o acesso às práticas sociais de leitura e de escrita, assim como permitir que as técnicas do sistema de escrita alfabética sejam aprendidas, pois são capacidades indispensáveis para a formação de crianças leitoras e produtoras de textos orais e escritos.

Entendemos que por meio do planejamento o professor pode organizar, didática e pedagogicamente, o trabalho a ser desenvolvido e o tempo a ser destinado para cada ação alfabetizadora. Essa tarefa exige dedicação do professor e ao mesmo tempo compreensão da responsabilidade de contemplar em cada etapa de elaboração, aplicação, avaliação e readequação do planejamento as dimensões teóricas e práticas que irão possibilitar superar as necessidades apresentadas pelo contexto heterogêneo de uma sala de aula de alfabetização.

A alfabetização na perspectiva do letramento é outro desafio que identificamos na prática alfabetizadora. Para Soares (2006, p. 47), "teríamos alfabetizar e letrar como duas ações distintas, mas não inseparáveis, ao contrário, alfabetizar letrando seria ensinar a ler e a escrever no contexto das práticas sociais da leitura e da escrita, de modo que o indivíduo se tornasse, ao mesmo tempo, alfabetizado e letrado". Isto é, para essa autora, o conceito letramento pode ser definido como resultado da ação de ensinar e aprender as práticas sociais de leitura e escrita, ou, em outras palavras, o estado ou condição que adquire um grupo social ou indivíduo como consequência de ter-se apropriado da escrita e de suas práticas sociais.

Soares (2003) evidencia que, no Brasil, os conceitos de alfabetização e letramento se mesclam, sobrepõem-se e, frequentemente, confundem-se. Para essa autora isso não é bom, pois os processos de alfabetizar e letrar são específicos. Alfabetizar é ensinar o código alfabético, letrar é familiarizar o aprendiz com os diversos usos sociais da leitura e da escrita. Soares (2003), ao explicar o surgimento da palavra letramento no vocabulário dos educadores brasileiros, menciona que hoje vivenciamos uma nova realidade social, em que não basta apenas saber ler e escrever, é preciso saber fazer uso do ler e do escrever, saber responder às exigências de leitura e de escrita que a sociedade faz continuamente.

Já Correa (2017) enfatiza que letrar alfabetizando ou alfabetizar letrando seria uma possibilidade de garantir aos alunos a aprendizagem do sistema alfabético e ortográfico da língua escrita ao mesmo tempo em que ocorreria a inserção destes nas práticas sociais da cultura escrita. Um dos maiores desafios dos professores alfabetizadores é atingir o objetivo de ensinar a ler para transformar informações em conhecimento, conciliando a apropriação do sistema alfabético/ortográfico e a plena condição do uso da língua nas práticas sociais de leitura e escrita.

Entrelaçado aos desafios já citados, encontra-se o desafio da avaliação do processo de ensino e aprendizagem no ciclo de alfabetização. Nossa concepção de avaliação vai além da visão tradicional, que focaliza o controle externo do aluno e é evidenciada através de notas ou conceitos. Compreendemos a avaliação como parte integrante e intrínseca ao processo educacional. Ainda entendemos que a avaliação não deve se restringir ao julgamento sobre sucessos ou fracassos do aluno.

As avaliações diagnósticas - a qual abordamos no desafio um - são utilizadas para detectar quais saberes as crianças já dominam, tornando-se um ponto de partida para o planejamento de estratégias para envolvê-las nos processos de ensino e de aprendizagem. Para Santiago (2015), quando tratamos de uma avaliação na esfera diagnóstica objetivamos antecipar o modo pelo qual a alfabetizadora deverá encaminhar, através do planejamento, a sua ação educativa visando a uma aprendizagem mais eficaz. Essa avaliação diagnóstica auxilia na definição de estratégias, considerando o tempo previsto para as aprendizagens. A partir dessa avaliação diagnóstica cabe ao professor desenvolver um plano de trabalho para que cada aluno se alfabetize. 
Ao considerarmos a avaliação na alfabetização é preciso integrar ao processo oportunidades aos alunos para novas possibilidades de aprender. Sabemos que esse fazer é desafiador tendo em vista que os tempos de aprendizagem e a realidade social de cada criança são singulares. Conforme exporto no Caderno de Apresentação do PNAIC (BRASIL, 2012a, p. 23), "a avaliação, portanto, deve ser encarada como um processo de pesquisa, no qual os integrantes da escola analisam as condições de ensino e de aprendizagem e estabelecem estratégias para melhorar a qualidade do trabalho realizado com as crianças". Entendemos que a avaliação contínua auxilia o professor alfabetizador no diagnóstico, no acompanhamento e em novas propostas para o desenvolvimento dos estudantes, diversificando as estratégias utilizadas para melhorar a aprendizagem dos alunos.

Nossa compreensão é de que o processo de alfabetização é um desafio constante. Não limitamos os desafios do processo de alfabetizar crianças aos acima listados; tantos outros podem ser possíveis. Contudo, o que percebemos a partir dos quatro desafios elencados é que os seus enfrentamentos são necessários para que se fortaleça o ensino instigante e a aprendizagem significante. Para tal, a formação e a atuação do professor alfabetizador são imprescindíveis.

Assim, as práticas educativas no ciclo de alfabetização precisam considerar a escrita como um objeto de conhecimento para a criança. Em palavras de Ferreiro (1988, p. 24), os "altos e baixos do desenvolvimento do conhecimento específico em relação ao sistema de escrita, dependem de modo íntimo da informação fornecida pelo ambiente", pois “o modo através do qual a informação é dada determina suas possibilidades de assimilação". 0 que significa que, para ser assimilada, a informação deve estar integrada a um determinado sistema, esteja ele elaborado previamente ou em processo de elaboração.

Compreendemos, então, que o ambiente alfabetizador precisa estar vinculado à múlti- plos significados. De acordo com Teberosky e Colomer (2003), um ambiente alfabetizador é aquele em que há uma cultura letrada, com livros, textos - digitais ou em papel -, um mundo de escritos que circulam socialmente. Para essas autoras, a inserção da língua escrita no cotidiano do alfabetizando deve incluir um ambiente alfabetizador organizado de forma que se constitua uma ferramenta de aprendizagem, e que inclua diversos gêneros textuais, os quais devem estar acessíveis aos alunos, permitindo uma interação com eles.

Em se tratando do desenvolvimento de estratégias para o ensino e aprendizagem do ler e do escrever, Soares (2003) dá destaque à reinvenção da alfabetização e atrela-a à recuperação da especificidade do processo de alfabetizar. No entanto, essa autora menciona que é preciso ter alguns cuidados para a não retomada de velhos métodos de alfabetização - que também representavam "fracassos" escolares - ou a retomada do método fônico. Soares (2003) enfatiza que avançar nos processos de alfabetização significa aprender com o passado e unir a ele as novidades do presente, as quais devem ter a inclusão da orientação para a construção de relações fonema/grafema e o estabelecimento de princípios, e não somente de métodos para alfabetizar.

De tal modo, uma prática educativa necessária no contexto da alfabetização é o fornecimento de ferramentas para que as crianças possam registrar, interpretar e transformar a informação. Para Ferreiro (1988), a ligação entre a linguagem impressa e a linguagem oral não é percebida pelas crianças imediatamente, pois elas formarão várias hipóteses e transformarão o conteúdo durante um longo processo, antes de entender essa ligação. A partir desses aspectos, nota-se a importância do papel do professor como um estimulador do desenvolvimento dessas aprendizagens nas crianças.

Umas das ferramentas que o professor pode usar no processo de alfabetização é o lúdico. Atividades lúdicas contribuem para a 
apropriação significativa dos conteúdos, uma vez que o trabalho com crianças das turmas de alfabetização envolve o universo imaginário da infância. Além disso, do ponto de vista didático "as brincadeiras promovem situações em que as crianças aprendem conceitos, atitudes e desenvolvem habilidades diversas, integrando aspectos cognitivos, sociais e físicos." (BRASIL, 2012b, p. 7). Para tanto, sugere-se que as metodologias levem em consideração as características da idade das crianças, em todos os sentidos, para que os processos de ensino e aprendizagem sejam significativos e eficazes. Dessa forma, o trabalho com elementos concretos e lúdicos otimiza a compreensão e a aprendizagem.

Oliveira (2016, p. 96) ainda destaca que o lúdico "constitui-se como um instrumento didático que facilita e motiva a construção do conhecimento significativo que auxilia no desenvolvimento de habilidades e do pensamento da criança". Segundo essa autora, a proposta lúdica deve contemplar "as necessidades dos estudantes de modo que eles possam aprender, a partir de jogos e brincadeiras, a leitura, a escrita e a ampliar suas referências culturais" (OLIVEIRA, 2016, p. 96). Evidenciamos que a ludicidade pode desenvolver a criatividade e mobilizar o processo de aprendizagem a partir das interações entre as crianças.

A prática educativa na alfabetização precisa considerar o ato de leitura como um processo de coordenação de informações de diversas procedências. Na visão de Cagliari (1993), ler é decifrar e buscar informações. Para esse autor, o segredo da alfabetização é a leitura, pois alfabetizar é, na sua essência, ensinar alguém a ler, ou seja, a decifrar a escrita. Assim, escrever ocorre em decorrência da leitura, e não o inverso. Cagliari (1993) ainda menciona que, na prática escolar, parte-se sempre do pressuposto de que o aluno já sabe decifrar a escrita, por isso o termo "leitura" adquire outro sentido e trata-se, então, da leitura para conhecer um texto escrito. Na alfabetização, a leitura como decifração é o objeto maior a ser atingido.
Em sala de aula, uma das dificuldades da leitura é o fato de os alunos não conseguirem decifrar as letras, não organizarem as ideias para pronunciar as palavras, pois não basta a simples articulação de sons da fala para que uma pessoa entenda o que está sendo dito. Cagliari (1993) ressalta que, quando lê, uma pessoa precisa, em primeiro lugar, arranjar as ideias na mente para montar a estrutura linguística do que vai dizer em voz alta ou simplesmente passar pelo seu pensamento. Esse autor cita que, em ambos os casos, a passagem pela estrutura linguística é essencial e sem isso não existe linguagem, e, portanto, não pode existir fala nem leitura de nenhum tipo.

Segundo Ferreiro (1988), é possível aceitar que nenhuma aprendizagem começa do zero e, assim sendo, a bagagem de esquemas interpretativos da criança é determinante no processo de assimilação da informação. Isto é, a necessidade de estudar as atividades de interpretação e processamento dos diversos textos, antes do processo de alfabetização, visa valorizar os conhecimentos prévios que as crianças possuem.

Mais um aspecto envolto às práticas de alfabetização é mencionado por Soares (2008), ao abordar que é primordial entender o papel da alfabetização dentro do processo de luta contra a discriminação e as injustiças sociais. Ainda que não seja imprescindível ao exercício da cidadania, a alfabetização é um instrumento para que a população conquiste os seus direitos, tanto sociais quanto políticos e civis. Portanto, o docente, como promotor da alfabetização, deve outorgar ao aluno ferramentas para que ele se aproprie verdadeiramente da leitura e escrita e, consequentemente, se integre à cultura letrada, destacando neste caso a importância de não apenas oportunizar alfabetização, mas também letramento às crianças.

Ressalta-se, assim, a necessidade de considerar os aspectos sociais e políticos que condicionam a aprendizagem da leitura e escrita, a partir da marca de discriminação em favor das classes socioeconômicas privilegiadas, que 
gera nas classes populares dificuldade para se adaptar e responder às expectativas da escola às funcionalidades, seus usos da língua escrita e, consequentemente, o fracasso escolar, causado em grande medida pelo preconceito, bem como pelo entendimento da aprendizagem como "neutra", desconsiderando o seu caráter político.

Pensar a figura do professor alfabetizador demanda compreender que a reflexão sobre as experiências e as práticas são fundamentais para a formação desse profissional. A reflexão como princípio de formação assume importante referência para os docentes. Nóvoa (1995) aponta a compreensão de que os percursos da vida do professor implicam em valorizar seu trabalho de reflexão sobre suas práticas e experiências coletivas na sua formação. Para esse autor, a teoria fornece pistas de leitura, mas o adulto retém aquilo que está ligado à sua experiência. Afirma ainda que a formação não se constrói por acumulação - de cursos, de conhecimentos ou de técnicas -, mas, sim, através de um trabalho de reflexividade crítica sobre as práticas de re(construção) permanente de uma identidade pessoal, por isso é tão importante investir na pessoa e dar um estatuto ao saber da experiência.

Pimenta (2005, p. 20) se aproxima da ideia de Nóvoa (1995) quando considera que "os saberes da experiência são também aqueles que os professores produzem no seu cotidiano docente, num processo permanente de reflexão sobre a prática [...]". Podemos perceber que a experiência oportuniza aos saberes docentes uma reflexão significativa da dinâmica da profissão. Considerando também que o próprio exercício profissional, assim como os demais fatos cotidianos - compreendidos por ocorrências políticas, experiências, concepções teorias, práticas e outras conjunturas formativas -, irão compondo os saberes docentes.

Há um conjunto de saberes necessários à formação docente, denominados por Pimenta (2005) de saberes da docência, compreendidos pelos saberes da experiência, os saberes do conhecimento e os saberes pedagógicos. Segundo Pimenta (2005), os saberes da experiência referem-se a saberes que os professores desenvolvem baseados em seus trabalhos cotidianos e no conhecimento do seu contexto. Surgem da experiência e são por ela legitimados. Incorporam-se à experiência, na forma de habilidades, de saber-fazer e de saber-ser. Para essa autora, os saberes da experiência são aqueles que os professores produzem no seu cotidiano docente, num processo permanente de reflexão sobre sua prática, em contato com seus colegas de trabalho e também com os textos produzidos por outros educadores. Por isso destaca-se a importância, para a formação dos professores, dos processos de reflexão sobre a própria prática e do desenvolvimento das habilidades de pesquisa.

Os saberes do conhecimento referem-se aos saberes teóricos, que vão além da simples informação. 0 domínio do saber do conhecimento significa, além de adquirir informação, saber trabalhar/compreender essa informação, classificando-as, analisando-as e contextualizando-as, produzindo assim novas formas de conhecimento (PIMENTA, 2005). Já os saberes pedagógicos são os conhecimentos necessários para o ensinar, uma vez que se considera que a experiência e os conhecimentos específicos não são suficientes para a prática docente (PIMENTA, 2005). Os "saberes pedagógicos podem colaborar com a prática” (PIMENTA, 2005, p. 27) e vinculam-se com a didática, constituída por ser um campo da pedagogia que se ocupa dos métodos e técnicas de ensino.

Ainda Pimenta (2005) esclarece que os saberes docentes não são formados apenas da prática, sendo também nutridos pelas teorias da educação. Neste entendimento, compreender as especificidades dos saberes docentes precede considerar toda a multiplicidade que compõe o trabalho docente, tanto em seus aspectos profissionais, como pessoais, de suas experiências circundantes e da aproximação com a reflexão constante que irão nortear as práticas pedagógicas dos professores. 
Para Libâneo (2012), a reflexividade é uma característica dos seres racionais conscientes que consiste em uma autoanálise sobre as suas próprias ações. Esse autor ainda propõe três significados diferentes para esta noção. 0 primeiro é a reflexividade como consciência dos meus próprios atos, isto é, como o ato de pensar sobre mim mesmo, sobre o conteúdo da minha mente (reflexão interior). 0 segundo menciona a reflexão como uma relação direta entre a minha reflexividade e as situações práticas, neste caso, a reflexividade é vista como algo imanente à minha ação, sem ser retrospectiva. E o terceiro é a reflexividade vista desde uma reflexão dialética, em que uma realidade independente pode ser captada pela minha reflexão.

Segundo Libâneo (2012), cada um desses sentidos da reflexividade gera diferentes entendimentos do seu papel no trabalho dos professores, ao reconhecer que de forma geral o papel da reflexão na prática docente está vinculado ao entendimento da escola como uma comunidade crítica de aprendizagens e ao aprimoramento do trabalho. Ainda a respeito do lugar da reflexividade na formação inicial e continuada de professores e, portanto, no seu desenvolvimento profissional, Libâneo (2012, p. 65) aponta que "o cerne da reflexividade está na relação entre o pensar e o fazer, entre o conhecer e o agir".

Por sua vez, Pimenta (2012) esclarece que a expressão "professor reflexivo" torna-se, durante o início dos anos 1990, um movimento teórico de compreensão do trabalho docente. Isso se evidencia a partir dos postulados de Schön, que vieram contribuir com a valorização da prática desde os primeiros anos da formação dos docentes, considerando como exemplo a prática de outros professores. Assim, a prática não se situa apenas no final do curso, por exemplo, com o desenvolvimento do estágio. Entretanto, é necessário ressaltar que a prática deve ser refletida, que venha auxiliar o professor nas mais diversas situações que os contextos educativos possam vir apresentar. Essa autora ainda salienta que a prática reflexiva deve ser contextualizada, pois se trata da aquisição de uma postura crítica, isto é, de uma reflexão coletiva que incorpore a análise dos contextos e tenha um compromisso de transformação das desigualdades sociais, considerando outros grupos da comunidade e o que eles têm a dizer sobre os problemas educativos. Em se tratando da alfabetização, a reflexão também assume destaque nas práticas pedagógicas. Para tanto, o professor alfabetizador constrói sua essência pessoal e profissional nos fazeres diários e na prática constante de refletir ao ensinar e ao aprender enquanto ensina.

\section{A repercussão da formação do PNAIC nas práticas alfabetizadoras}

Para pesquisar, segundo as professoras, quais aspectos da formação do PNAIC fazem parte de suas práticas alfabetizadoras, em nossa coleta de dados solicitamos que as professoras fizessem uma comparação entre suas práticas desenvolvidas antes e depois do PNAIC. No Quadro 1 apresentamos suas respostas referentes à caracterização das práticas anteriores ao PNAIC.

Quadro 1 - As práticas alfabetizadoras anteriores ao PNAIC

\begin{tabular}{|l|c|}
\hline Unidades de análise & Incidências \\
\hline Pouca utilização da ludicidade & 2 \\
\hline Pouca compreensão sobre a alfabetização na perspectiva do letramento & 2 \\
\hline Não explorava a leitura e a escrita com função social & 1 \\
\hline Pouca compreensão dos níveis de escrita & 1 \\
\hline Pouco registrava o processo de alfabetização dos alunos & 1 \\
\hline
\end{tabular}

Fonte: Elaborado pelas autoras deste artigo com base em dados da pesquisa. 
Em relação às práticas alfabetizadoras antes da participação no PNAIC, duas professoras argumentaram que utilizavam pouco a ludicidade: "Antes, falando da minha experiência, eu era até mais técnica [...]. A gente não se dava conta do tanto que a gente poderia ampliar para a ludicidade trazendo aquele determinado conteúdo." (ANA); "[O PNAIC] trouxe muito a questão lúdica, lógico que tive muito que aprender. Digamos que eu era menos lúdica ou menos pautada, menos enriquecida nesses critérios da alfabetização até o conhecimento de todo esse processo [apresentado pelo PNAIC]." (BRENDA).

Parece-nos, com base nos posicionamentos das professoras, que suas práticas alfabetizadoras antes do PNAIC estavam condicionadas a um ensino mais técnico, ao qual não incluíam efetivamente o uso da ludicidade. Talvez essa característica se tornasse um aspecto limitante à ação de aprender dos alunos. Entendemos que as atividades lúdicas se relacionam aos jogos e ao ato de brincar, os quais são elementos importantes para a aprendizagem, uma vez que, do "ponto de vista didático, as brincadeiras promovem situações em que as crianças aprendem conceitos, atitudes e desenvolvem habilidades diversas, integrando aspectos cognitivos, sociais e físicos" (BRASIL, 2012b, p. 7). Portanto, a ludicidade aplicada aos processos de ensinar e aprender na alfabetização pode desenvolver conhecimentos e a criatividade, inclusive mobilizando a interação e a construção de saberes entre as próprias crianças.

Duas professoras argumentaram ter, antes da formação do PNAIC, pouca compreensão sobre a alfabetização na perspectiva do letramento: "[0] conceito do letramento passou a entrar de forma muito incisiva nas formações do PNAIC e fazia com que a gente analisasse as nossas práticas." (ISABELA); “O PNAIC trouxe muito a fala da alfabetização na perspectiva do letramento, [trouxe a compreensão de que] o letramento é mais amplo do que o ler e escrever propriamente dito." (BRENDA).
Para Correa (2017, p. 27), letrar "alfabetizando ou alfabetizar letrando seria uma possibilidade de garantir aos alunos a aprendizagem do sistema alfabético e ortográfico da língua escrita ao mesmo tempo em que ocorreria a inserção destes nas práticas sociais da cultura escrita". Em análise às respostas, compreendemos que a partir da formação que tiveram no PNAIC, por meio dos textos estudados e dos contextos vivenciados, as professoras puderam relacionar o conceito de letramento aos seus fazeres docentes. Compreendemos que tal procedimento pedagógico oportunizará à criança aprendizagens mais significativas, em que a leitura e a escrita terão relação com o contexto ao qual se ensina e se aprende.

Uma das entrevistadas expôs que, antes de participar da formação continuada do PNAIC, não explorava a leitura e a escrita com função social:

A formação do PNAIC trouxe uma discussão para os professores que é da função social da leitura e da escrita. Uma visão minha de professora alfabetizadora há alguns anos atrás era de que a decodificação, o reconhecimento dos sons das letras, o reconhecimento das palavras e uma letra bonita eram fundamentais para a alfabetização. (ISABELA).

Compreendemos, a partir da resposta da alfabetizadora, que há algum tempo ela associava o ensino da alfabetização à decodificação e pouco refletia sobre a função social da leitura e da escrita. Para Soares (2008), a alfabetização se desenvolve no contexto de e por meio de práticas sociais de leitura e escrita, através de atividades de letramento. Já o letramento só se desenvolve no contexto da e por meio da aprendizagem das relações fonema/grafema, ou seja, em dependência com a alfabetização (SOARES, 2008). Compreendemos que o ensinar a ler e a escrever, sem oportunizar aos alunos uma aproximação com o mundo letrado - dando ênfase à língua como um sistema e não como um bem cultural/social -, caracteriza-se por privar as crianças de conhecimentos/informações significativas, que podem oportunizar o acesso ao meio social letrado. 
Outro argumento de uma das professoras foi que, anteriormente aos estudos do PNAIC, ela pouco compreendia os níveis de escrita: “O PNAIC conseguiu deixar muito mais claro essa questão dos níveis de escrita." (GABRIELA).

A compreensão dos níveis de escrita é condição fundamental para os alfabetizadores potencializarem metodologias que permitem um trabalho coerente com a aprendizagem de cada criança. Ferreiro e Teberosky (1979), quando tratam da Psicogênese da Língua Escrita, referem que a criança passa por níveis de apropriação do sistema de escrita alfabética, que consiste em supor que é necessária uma série de processos de reflexão sobre a linguagem para passar a uma escrita. Esses níveis são estruturados em $1^{\circ}$ período: nível pré-silábico, 2o período: nível silábico, $3^{\circ}$ período: nível silábico alfabético e $4^{\circ}$ período: nível alfabético. Dado o exposto, após a identificação dos níveis de escrita de cada estudante, o desafio principal do professor alfabetizador é eleger e diversificar as atividades conforme cada nível de aprendizagem. Une-se a isso a ideia de que a criança "é o ponto de partida de toda aprendizagem." (FERREIRO; TEBEROSKY, 1979, p. 32). Identificar o que a criança já sabe e o que ela ainda não sabe é uma questão referencial para sequenciar as próximas metodologias de ensino, tendo em vista a alfabetização. Segundo a professora Gabriela, antes da participação do PNAIC ela não possuía clareza desses distintos períodos do processo de apropriação da língua escrita de seus alunos - o que poderia estar limitando suas práticas alfabetizadoras.

Uma das entrevistadas enfatizou que, antes de sua formação no PNAIC, pouco registrava do processo de alfabetização dos seus alunos. Para a alfabetizadora, "com o PNAIC a gente aprendeu muito essa parte de ter um registro, ter uma parte que você possa ver: aqui meu aluno avançou, aqui está a dificuldade, aqui eu tenho que voltar, replanejar e continuar" (FABIANE).

Evidenciamos, a partir do posicionamento dessa professora, que o registro do processo de alfabetização é importante e necessário para nortear a prática docente. A partir da avaliação diagnóstica, do acompanhamento diário do desenvolvimento das aprendizagens de cada aluno, o professor pode fazer registros que irão direcioná-lo para a elaboração de planejamento mais coerente. Santiago (2015, p. 62) enfatiza que "quando tratamos de uma avaliação na esfera diagnóstica objetivamos antecipar o modo pelo qual a alfabetizadora deverá encaminhar, através do planejamento, a sua ação educativa; estabelecer os limites para tornar o processo de aprendizagem mais eficaz". Ao alfabetizar, o professor segue uma sequência de ações pedagógicas que favorece o avanço de cada criança para o próximo nível de leitura e escrita. Nessa sequência de ações está também o processo avaliativo que permite ao professor evidenciar as aprendizagens alcançadas e as aprendizagens a serem desenvolvidas pelos alunos.

Todas as professoras relataram que, após a participação no PNAIC, efetivaram mudanças em suas práticas. Algumas das limitações reconhecidas nas práticas das docentes, anteriores às suas formações do PNAIC, evidenciaram-se, consequentemente, como aprendizagens decorrentes do processo formativo. No Quadro 2 apresentamos suas respostas referentes à caracterização de suas práticas posteriores ao PNAIC.

Quadro 2 - As práticas alfabetizadoras posteriores ao PNAIC

\begin{tabular}{|l|c|}
\hline Unidades de análise & Incidências \\
\hline Contribuições da teoria para a prática & 3 \\
\hline Avaliação dos níveis de escrita dos alunos & 3 \\
\hline Maior uso da ludicidade & 2 \\
\hline Importância do planejamento & 1 \\
\hline Compreensão da função social da leitura e da escrita & 1 \\
\hline
\end{tabular}

Fonte: Elaborado pelas autoras deste artigo com base em dados da pesquisa. 
Após a formação do PNAIC, um argumento encontrado nas respostas de três das professoras se direcionou para as contribuições da teoria para a prática:

A teoria é importante sim. E essa formação trazendo a teoria, trazendo as leituras, trazendo essas fontes, nos fez retornar, nos fez rebuscar, mexeu com aquela coisa que estava mais 'acomodadinha' e foi bem interessante. (ANA).

Depois da formação do PNAIC, com [...] o material que vinha para estudo [...] eu consegui levar muita coisa para sala de aula. (BRENDA).

Agora, toda vez que a gente vai fazer alguma coisa, a gente lembra daquilo que a gente [...] leu. Daí a gente faz um pouco mais diferente ou faz com aquela convicção de que realmente é certo. (ROSA).

Esses posicionamentos revelam-nos que os estudos das teorias, que as professoras vivenciaram no PNAIC, as fizeram refletir sobre suas práticas. Tal aspecto vai ao encontro do que esclarece Pimenta (2005, p. 26) ao considerar que "os saberes docentes não são formados apenas da prática, sendo também nutrido pelas teorias da educação". A teoria é fundamental para o aprimoramento do fazer docente, uma vez que possibilita o aperfeiçoamento profissional, favorece a compreensão do contexto e a construção de uma ação pedagógica situada. Compreendemos que, por exemplo, ao se apropriar das contribuições teóricas relacionadas à aprendizagem, os educadores conseguem adequar suas formas de trabalhar com os desafios que surgem no processo de alfabetização e, assim, construir possibilidades pedagógicas mais coerentes.

Três professoras também expressam que a formação do PNAIC possibilitou uma melhor compreensão da avaliação dos níveis de escrita dos alunos:

O PNAIC conseguiu deixar muito mais claro para mim essa questão dos níveis de escrita [e assim] poder avaliar cada aluno em sua especificidade. Isso, para mim, foi uma possibilidade que o PNAIC apresentou. (GABRIELA).

Você ter mais clareza da atividade que você está fazendo e o nível de alfabetização de cada um e eles avançarem com mais segurança nesse processo, e eu como professora alfabetizadora também ter essa segurança no momento faz muita diferença. (FABIANE).

Você consegue ter a visão, hoje ele [aluno] conseguiu isso, amanhã ele vai conseguir aquilo [...] a evolução dele, e isso dia a dia com um trabalho bem pautado, bem organizado [...] com registros. Então o aluno chega no final quase alfabetizado ou tendo a alfabetização concluída ainda no primeiro ano do ensino fundamental. (BRENDA).

Os posicionamentos das professoras nos permitem entender que, a partir da compreensão dos níveis de escrita de cada criança, as alfabetizadoras conseguiram ter mais clareza em avaliar as especificidades da aprendizagem de seus alunos. As avaliações diagnósticas dos níveis de escrita dos alunos são utilizadas para detectar quais saberes as crianças já dominam, tornando-se um ponto de partida para o planejamento de estratégias a fim de envolvê-las nos processos de ensino e de aprendizagem. Além disso, a partir de Ferreiro e Teberosky (1979) entendemos que, para se alfabetizar, a criança precisa perceber que o que a escrita alfabética registra no papel são os sons das partes orais das palavras e que o faz considerando segmentos sonoros menores que a sílaba. Nesse aspecto, compreender com propriedade todo esse processo de construção da aprendizagem do Sistema de Escrita Alfabética (SEA), tende a auxiliar o professor alfabetizador a ter maior clareza em sua avalição e maior discernimento para a escolha das metodologias necessárias para auxiliar as crianças a avançar de um nível de escrita para o outro e consolidar o processo de alfabetização.

Outro apontamento encontrado nas respostas de duas professoras foi que, após a formação do PNAIC, houve maior uso da ludicidade no processo de alfabetização: "O PNAIC rebuscou, ele refrescou a nossa memória em relação [...] a atividades bem mais lúdicas." (ANA); “0 PNAIC trazia essa nova visão de, sim, trabalhar o conteúdo, e você tentar sempre trazer isso para o lado lúdico, para se tornar significativo [ao aluno]." (FABIANE). 
Oliveira (2016, p. 96) também pesquisou os desdobramentos do PNAIC na formação de professoras alfabetizadoras e, em seu trabalho, destacou que o lúdico "constitui-se como um instrumento didático que facilita e motiva a construção do conhecimento significativo que auxilia no desenvolvimento de habilidades e do pensamento da criança". Além disso, para essa autora, a proposta lúdica de trabalho pedagógico - contemplado no PNAIC - é uma estratégia de ensino que pode contemplar as necessidades dos estudantes, permitindo que eles, a partir de jogos e brincadeiras, aprendam a ler e escrever, bem como ampliem suas referências culturais. Evidenciamos, nos posicionamentos das professoras, que pós-PNAIC suas práticas incluíram mais ludicidade. A resposta da professora Ana, quando expressou "rebuscou" e "refrescou a nossa memória", faznos pensar que as professoras já conheciam a proposta lúdica, mas não estavam explorando essa possibilidade na prática. Sabemos que as atividades lúdicas, enquanto metodologia alternativa, permitem que, por meio dos jogos e das brincadeiras, os alunos aprendam de maneira mais interativa.

Após a formação do PNAIC, a professora Isabela também relembrou a importância do planejamento para as suas práticas pedagógicas:

[...] toda vez que a gente vai planejar alguma coisa a gente tem consciência de que essa atividade que eu estou planejando não tem uma função somente de exercitar uma letra ou um som de uma letra. Logo em seguida eu vou sempre pensar alguma coisa que possa inserir uma função de comunicação para aquilo que eu estou fazendo. Então eu vou sair somente daquele caça-palavras ou cruzadinha ortográfico ou de sílaba e eu vou transformar isso numa leitura que tenha significado ou vou buscar uma forma comunicativa daquele texto, de maneira que as atividades que os alunos fazem não sejam só para a professora corrigir, elas passam a ter também um significado para aquela criança. [...] Eu vejo que tem que haver muito cuidado na hora do planejamento. Ele é levado mais em consideração por mim na hora de planejar, para que eu não fique somente sendo técnica na alfabetização. (ISABELA).

Percebemos no relato da professora que, após sua participação no PNAIC, ela passou a atribuir uma maior importância ao planejamento do seu trabalho pedagógico, evidenciando um olhar mais amplo ao processo de ensino. O planejamento é uma necessidade para o desenvolvimento das estratégias didáticas, que irão viabilizar o processo de alfabetização das crianças. Com respaldo em Soares (2003), compreendemos que o professor deverá organizar o processo de construção da leitura e da escrita de forma sistemática e metodológica. Cabe ao docente perceber que planejar deve ser uma atividade consciente e que incorpore a previsão das ações pedagógicas referenciadas em uma didática concreta. Frente ao exposto, é inegável a responsabilidade do professor ao elaborar seu planejamento, responsabilidade essa assumida pela professora Isabela.

Outro argumento citado pela professora Isabela foi que a formação continuada do PNAIC oportunizou uma melhor compreensão da função social da escrita:

O que eu compreendi depois do PNAIC foi a função social da escrita. [...] Durante as formações a gente leu relatos de outros professores de como que uma prática que era bem fechada por exemplo, decorar uma lista de palavras com uma determinada sílaba - ficou completamente diferente quando se colocou esse texto a serviço de uma função social - como fazer uma lista de compras pra ir ao mercado, redigir um bilhete para enviar alguma informação, receber alguma informação da direção da escola ou da outra turma ou mesmo um texto que fosse literário e que a gente pudesse transformar esse texto em um contexto que tivesse uma função social, que estive além da simples decodificação. (ISABELA).

O posicionamento da alfabetizadora trouxe a importância de vincular o processo de alfabetização às necessidades reais dos educandos. Vieira (2015, p. 38) lembra que o PNAIC defende que a aprendizagem de ler e escrever "requer considerar as práticas culturais de leitura e escrita, observando que o estudante 
é capaz de construir conhecimentos e participar de modo ativo nos diferentes espaços de interlocução, defendendo princípios e valores". Tanto a fala da professora Isabela quanto o excerto de Vieira (2015) enfatizam que no processo de ensino do sistema de escrita alfabética deve-se valorizar as vivências que cada criança traz consigo, para que, assim, o aprendiz perceba-se no contexto e relacione as habilidades de leitura e escrita às suas necessidades e interesses.

As professoras alfabetizadoras também foram questionadas sobre suas percepções referentes aos impactos do PNAIC para a aprendizagem dos alunos. No Quadro 3 podemos observar as respostas obtidas.

Quadro 3 - Impactos do PNAIC para a aprendizagem dos alunos

\begin{tabular}{|l|c|}
\hline Unidades de análise & Incidências \\
\hline Trouxe clareza dos direitos de aprendizagens dos alunos & 2 \\
\hline Proporcionou a organização da rotina da alfabetização & 2 \\
\hline Alunos como centro da aprendizagem & 2 \\
\hline
\end{tabular}

Fonte: Elaborado pelas autoras deste artigo com base em dados da pesquisa.

Percebemos nas respostas das professoras que a participação delas no PNAIC trouxe impactos na aprendizagem de seus alunos. Algumas delas consideraram que a formação oportunizou entender com clareza os direitos de aprendizagem, das crianças em processo de alfabetização. Duas das professoras comentaram:

[O PNAIC] trouxe para nós toda aquela questão bem mais pontuada dos direitos de aprendizagem e isso foi fundamental, fazendo com que a gente refletisse mais sobre o nosso dia a dia. [...] Assim: 'Hoje esse conteúdo atingiu os direitos de aprendizagem dele?' 'O que que eu fiz ou poderia ter feito para que ele atingisse esses direitos?' (ANA).

O PNAIC trouxe muito dos direitos de aprendizagens dos alunos, o direito de aprender do aluno. A gente precisa valorizar o crescimento do aluno no dia a dia de sala de aula nesse processo de alfabetização. (BRENDA).

Em seus estudos, Oliveira (2016) também enfatiza que o PNAIC apresentou para os professores alfabetizadores os direitos de aprendizagem. Esses direitos tratam dos conhecimentos que a criança "precisa aprender a cada ano, o que auxilia a organização das práticas pedagógicas do alfabetizador que ao verificar quais direitos ainda não foram apropriados pelos alunos, estabelece em seus objetivos o trabalho para alcançá-los" (OLIVEIRA 2016, p. 71). Parece-nos que, a partir da participação no PNAIC, as professoras Ana e Brenda esclareceram seus compromissos com o respeito e a garantia dos direitos de aprender de seus alunos.

Duas das professoras entrevistadas argumentaram que a organização da rotina da alfabetização, incitada pelo PNAIC, pode ter contribuído para com as aprendizagens de seus alunos:

A rotina que eu fazia não era elaborada, dentro de uma ordem, dentro de uma organização que todo dia precisava acontecer. Então, a partir do PNAIC eu comecei a ter essa nova visão. [...] Você analisa eles no início do ano e você tem um objetivo para o final de ano [...] e você vê a progressão deles, a evolução deles no dia a dia com um o trabalho bem pautado, bem organizado, bem dentro da rotina [...] isso foi muito bom. (BRENDA).

Como eu sou alfabetizadora há alguns anos, lá atrás, quando eu comecei a trabalhar unidades e dezenas, por exemplo, vamos dizer que era meio estagnado, era um momento de trabalhar unidades e dezenas. Com a formação do PNAIC, passei a ter um olhar diferente, passei a trabalhar com isso desde o início do ano, do primeiro dia da data, a partir do calendário, das fichas escalonadas que trabalham a composição dos números. (GABRIELA). 
No relato da professora Gabriela, percebemos que ela inseriu novas possibilidades de ensino à sua rotina de alfabetização. Ambas as professoras relataram que consideram que com a reorganização da rotina de alfabetização passaram a estimular melhor o desenvolvimento das aprendizagens de seus alunos. Em Soares (2003) elucidamos que, para a organização da rotina, é necessário considerar e articular uma clara definição dos objetivos da alfabetização, da opção conceitual, da definição das ações, procedimentos e técnicas para atingir tais finalidades, não apenas estabelecendo um conjunto de prescrições geradoras de uma prática rotineira. Essas considerações sobre a rotina fazem-nos afirmar que, em se tratando das práticas de alfabetização, é importante que o alfabetizador reflita sobre o que ensina, por que ensina, como ensinar, quando ensinar e quais tempos são necessários para que esse ensino se efetive como aprendizagem para as crianças.

Para duas alfabetizadoras, a participação no PNAIC oportunizou aos alunos estarem no centro da aprendizagem:

Uma coisa que eu faço nas turmas é assim: antes da minha correção eles leem e dão sugestões uns para os outros, de como aquela frase pode ficar melhor, se o texto está confuso, se pode melhorar alguma parte, acrescentar alguma coisa, a parte ortográfica também, se alguma palavra não está correta. Eles têm esse olhar que é um olhar de organização do texto, é um olhar de conteúdo do texto, é um olhar da escrita desse texto. Quando esses textos ganham essa outra dimensão para as crianças, têm muito mais significado, e a alfabetização não se torna um ato mecânico, mas um ato social; se torna um ato de interação social quando a leitura e escrita estão incluídas nisso aí tudo. (ISABELA).

O que eu fiz diferente foi a questão das leituras. No começo eu fazia [a leitura para os alunos] e depois eu deixava os alunos fazerem a leitura que eles quisessem: de uma notícia, de uma piada, de uma história. Aquilo para eles era muito bom, porque eles também iam atrás da busca de alguma leitura ou eu deixava livros expostos para eles. Isso foi uma coisa que até hoje eu faço e que a gente vê que é importante para despertar neles esse gosto para a leitura. (ROSA).
Através dos posicionamentos das alfabetizadoras, observamos que ambas oportunizaram que os alunos fossem protagonistas das práticas relatadas. Tais encaminhamentos pedagógicos favorecem às crianças a compreensão dos aspectos sociais das práticas de ler e escrever. Nesse sentido, buscamos, a partir de Soares (2008), enfatizar que a criança se alfabetiza, constrói seu conhecimento do sistema alfabético e ortográfico da língua escrita no seu contexto e por meio de interação com a realidade dos materiais escritos. Entendemos que as professoras, ao sistematizarem e contextualizarem as atividades de leitura e escrita, possibilitaram aos seus alunos aprofundar o diálogo entre as ações realizadas em sala de aula e suas vivências sociais diárias, tornando as atividades mais prazerosas e marcantes.

\section{Algumas considerações finais}

Neste estudo buscamos identificar e analisar quais aspectos da formação do Pacto Nacional Pela Alfabetização na Idade Certa (PNAIC) fazem parte das práticas alfabetizadoras das professoras após as etapas desta formação. Para tal, organizamos os dados e análises em três categorias. Na categoria denominada de práticas alfabetizadoras anteriores à formação do PNAIC evidenciamos que as práticas pedagógicas anteriores eram limitantes no tocante à ludicidade; à compreensão da alfabetização na perspectiva do letramento; à exploração da função social da leitura e da escrita; à compreensão dos níveis de escrita; e ao registro do processo de alfabetização dos alunos. Em relação à categoria das práticas alfabetizadoras posteriores ao PNAIC, as professoras relataram que a formação fortaleceu seus fazeres docentes pela contribuição da teoria; pela melhor avaliação dos níveis de escrita dos alunos; pelo maior uso da ludicidade; pelo reconhecimento da importância do planejamento; e pela compreensão da função social da leitura e da escrita. Já em se tratando da categoria impactos do PNAIC para a aprendizagem dos 
alunos, as professoras enfatizaram a tomada de conhecimentos referentes aos direitos de aprendizagens dos alunos; a importância da organização da rotina na alfabetização; e o envolvimento dos alunos como centro da aprendizagem.

Os embasamentos teóricos e os dados analisados nos permitem evidenciar que o processo de alfabetização possui elementos complexos e desafiadores relativos às práticas das docentes alfabetizadoras. Reafirmamos que alfabetizar envolve um trabalho de apropriação das práticas de leitura e de escrita pelos aprendizes, o que determina a competência do professor para tal função, pois envolve uma atividade pedagógica com múltiplos resultados ao final de um ciclo.

Observamos que o PNAIC foi relevante para as professoras alfabetizadoras, sendo uma formação significativa para seus processos de formação docente e para a ressignificação de suas práticas. Constatamos que essa formação continuada repercutiu na constituição docente e nas práticas alfabetizadoras das professoras, entre outros, por envolver as necessidades do cotidiano da escola, por articular os saberes e as experiências das professoras, por integrar teoria e prática. Assim, ressaltamos que as práticas de alfabetização podem ser alteradas por meio das novas experiências formativas e das compreensões obtidas por cada docente em formação.

Analisando as particularidades desta investigação, reconhecemos que ainda há muito espaço para a sequência de estudos sobre a formação continuada dos alfabetizadores. Acreditamos que cursos de formação de professores alfabetizadores, a exemplo do PNAIC, possibilitam uma aproximação reflexiva com os muitos elementos que compõem a docência e as práticas alfabetizadoras. Mesmo assim, em nossa compreensão, para que o processo formativo venha atingir objetivos coerentes, precisa estar articulado com os significados da realidade educativa dos docentes em formação. Para tanto, são dimensões essenciais para um desenvolvimento formativo coerente os elementos que submergem das necessidades do cotidiano da escola, os saberes e as experiências dos docentes, a reflexão sobre o ser e o atuar na docência alfabetizadora, a integração das teorias e das práticas de alfabetização, entre outros.

Por fim, consideramos que esses apontamentos não esgotam as possibilidades de análise sobre a formação e as práticas das professoras alfabetizadoras, mesmo assim, acreditamos ser imprescindível a compreensão de que o processo de alfabetização encontra-se envolto em um percurso complexo, que necessita ser constantemente orientado por estudos fundamentados e reflexivos.

\section{REFERÊNCIAS}

BOLZAN, Doris Pires Vargas; MILLANI, Silvana Martins de Freitas. Aprendizagem da docência alfabetizadora: desafios à formação. Revista Contrapontos, Itajaí, SC, v. 13, n. 3, p. 186-194, set./ dez. 2013.

BRAGA, Andreia Martinazzo. Processos formativos de professoras alfabetizadoras: um estudo a partir da formação continuada do Pacto Nacional pela Alfabetização na Idade Certa (PNAIC). 2019. Dissertação (Mestrado em Educação) - Programa de Pós-Graduação em Educação, Universidade do Oeste de Santa Catarina (Unoesc), Joaçaba, SC, 2019.

BRASIL. Ministério da Educação. Secretaria de Educação Básica. Diretoria de Apoio à Gestão Educacional. Pacto nacional pela alfabetização na idade certa: formação do professor alfabetizador: caderno de apresentação. Brasília, DF: MEC/SEB, 2012a.

BRASIL. Ministério da Educação. Secretaria de Educação Básica. Diretoria de Apoio à Gestão Educacional. Pacto nacional pela alfabetização na idade certa: ludicidade na sala de aula. Brasília, DF: MEC/SEB, 2012b.

CAGLIARI, Luiz Carlos. Alfabetização e linguística. São Paulo: Scipione, 1993.

CORREA, Regina Aparecida. Concepções de alfabetização e letramento: a voz de professoras participantes do Pacto Nacional pela Alfabetização 
na Idade Certa - PNAIC no município de Ouro Peto - MG. 2017. 151 f. Dissertação (Mestrado em Educação) - Instituto de Ciências Humanas e Sociais, Programa de Pós-graduação em Educação, Universidade Federal de Ouro Preto (UFOP), Ouro Preto, MG, 2017.

FERREIRO, Emília. Alfabetização em processo. São Paulo: Cortez, 1988.

FERREIRO, Emília. Com todas as letras. v. 2. São Paulo: Cortez, 1999.

FERREIRO, Emília; TEBEROSKY, Ana. Psicogênese da língua escrita. Porto Alegre: Artes Médicas, 1979.

FRANCO, Maria Amélia Santoro. Pedagogia e prática docente. São Paulo: Cortez, 2012.

LIBÂNEO, José Carlos. Reflexividade e formação de professores: outra oscilação do pensamento pedagógico brasileiro? In: PIMENTA, Selma Garrido; GHEDIN, Evandro (org.). Professor reflexivo no Brasil: gênese e crítica de um conceito. 7. ed. São Paulo: Cortez, 2012. p. 63-93.

NÓVOA, Antônio. Os professores e a sua formação. In: NÓVOA, Antônio (coord.). Formação de professores e profissão docente. 2. ed. Lisboa: Dom Quixote, 1995. p. 15-34.

OLIVEIRA, Marineiva Moro Campos de. Concepções e fundamentos do Pacto Nacional pela Alfabetização na Idade Certa e seus desdobramentos na formação de alfabetizadores na perspectiva de uma alfabetização emancipatória em Xaxim/SC. 2016. 181 f. Dissertação (Mestrado em Educação) - Programa de Pós-graduação em Educação, Universidade Estadual do Oeste do
Paraná (UNIOESTE), Francisco Beltrão, PR, 2016.

PIMENTA, Selma Garrido. Professor reflexivo: construindo uma crítica. In: PIMENTA, Selma Garrido; GHEDIN, Evandro (org.). Professor reflexivo no Brasil: gênese e crítica de um conceito. 7 . ed. São Paulo: Cortez, 2012. p. 20-62.

PIMENTA, Selma Garrido. Saberes pedagógicos e atividades docente. 4. ed. São Paulo: Cortez, 2005.

SANTIAGO, Luciane Teresinha Munhoz. As influências do PNAIC na dinâmica do processo de alfabetização. 2015. 143 f. Dissertação (Mestrado em Educação) - Centro Universitário La Salle (UNILASALLE), Canoas, RS, 2015.

SOARES, Magda. A reinvenção da alfabetização. Revista Presença Pedagógica, Belo Horizonte, v. 9, n. 52, p. 15-21, jul./ago. 2003.

SOARES, Magda. Alfabetização e letramento. 5. ed. São Paulo: Contexto, 2008.

SOARES, Magda. Letramento: um tema em três gêneros. 2. ed. Belo Horizonte: Autêntica, 2006.

TEBEROSKY, Ana; COLOMER, Teresa. Aprender a ler e escrever: uma proposta construtivista. Porto Alegre: Artmed, 2003.

VIEIRA, Claudia Figueiredo Duarte. Formação continuada de professores no Pacto Nacional pela Alfabetização na Idade Certa - PNAIC: do texto ao contexto. 2015. 156 f. Dissertação (Mestrado em Educação) - Programa de Pós-graduação em Educação, Universidade Federal do Piauí (UFPI), Teresina, 2015.

Recebido em: 10/03/2020

Aprovado em: 15/12/2020 